\title{
Da precarização do trabalho docente no Brasil e o processo de reestruturação produtiva
}

\section{Precariousness of teaching Job in Brazil AND THE RESTRUCTURING PROCESS OF PRODUCTION}

\author{
Lourival José de Oliveira * \\ Ana Paula Vicente Pires **
}

Resumo: Na história do constitucionalismo Brasileiro não havia indícios de valorização do profissional docente. Porém, com o advento da Constituição Federal de 1998, bem como na Lei de Diretrizes e Bases da Educação, em 1996, foi contemplado nos seus textos os princípios e as normas para a valorização dos professores. Em um Estado Democrático de Direito, o fundamento da preservação e promoção da dignidade da pessoa humana possui caráter absoluto, sendo que desta forma deve abranger o ambiente laboral como forma de consolidar a dignidade da pessoa quando do exercício do seu trabalho. O cenário educacional brasileiro, diferentemente do que propugna a legislação de proteção ao trabalhador docente, está impregnado pela desvalorização social do trabalho dos profissionais da educação. Concluiu-se que a atividade docente também passa por um processo de reestruturação produtiva, intensificado por uma ideologia de mercado que corrobora na desvalorização da função docente. Buscou-se de acordo com os princípios constitucionais gerais e específicos apresentar proposições que tenham como objetivo garantir o valor social educação, corroborando com a geração de um ambiente de trabalho digno para o desenvolvimento da atividade docente.

Palavras-chave: Profissionais da Educação. Reestruturação Produtiva. Desvalorização. Eficácia das Normas de Proteção.

Abstract: In Brazilian constitutionalism's history there was no evidence of professoriate's valorization. However, the 1988 Federal Constitution and the Brazilian Educational Laws and Guidelines (LDB) (1996) pondered the principles and standards concerning professors' recognition. In a democratic state, the human preservation and dignity principle is absolute, and thus should reach the working environment as a way of consolidating 
the person's dignity concerning job. The Brazilian educational scenario, unlike the law ruling the teaching activity, socially depreciates the teachers's paper. The professoriate has been through a restructuring process, intensified by a market ideology that supports the estimation of the teaching fun ction. Drawing to a close, some proposals in accordance with general and specific constitutional principles were shown aiming the social importance of education, strenghtening with the criation of a respectable workplace for teaching staff.

Keywords: Professoriate. Productive Restructuration. Devaluation. Effectiveness of Protection Standards. 


\section{INTRODUÇÃO}

A atividade docente pode ser considerada como a função mais sofisticada, visto que visa formar seres aptos para governarem a si mesmos, e estabelecer meios de relação social que propugna o progresso da nação brasileira. Em sua origem, o trabalho dos professores era desenvolvido mediante uma vertente religiosa, sendo que, quando o Estado tomou a seu cargo a instituição escolar no início do século XVIII, originou-se a profissionalização docente, conhecida como um processo de funcionarização dos professorado brasileiro.

A Constituição Federal de 1934 instituiu pela primeira vez a educação como um direito de todos, em que os saberes escolares se voltam para conhecimentos científicos e comportamentais, baseados em valores morais. Desde então, é essencial o papel do professor para garantir um direito social a todos os cidadãos, a educação.

Não restam dúvidas de que o principal patromônio do Sistema Educacional Brasileiro é a capacidade docente, tanto intelectual, como também técnica ou profissional, para desenvolver projetos, pesquisas e oportunizar a todos os cidadãos o direito social à educação, previsto no artigo $6^{\circ}$ da Constituição Federal vigente.

Diante da essencialidade do trabalho dos professores, a relevância do tema é tal que se faz necesário um estudo referente à evolução do ordenamento jurídico brasileiro, com fincas a esclarecer a origem das garantias ao trabalho docente, bem como da efetivação do princípio da valorização dos profissionais do ensino. Adota-se na elaboração deste artigo o método dedutivo

Em um primeiro momento, pretende-se identificar quais as normas de proteção ao trabalho docente no Brasil e quais as suas reais finalidades, meramente normatizar e regulamentar a organização laboral, ou se de fato busca garantir um trabalho digno aos profissionais da educação.

A situação de trabalho precário teve seu início associado à mudanças percebidas no mundo do trabalho ocorridas por volta da década de 1970 . No campo educacional, o neoliberalismo representou o estabelecimento de reordenações nos sistemas educacionais, momento em que houve uma redefinição do papel do Estado na sua relação com a educação, corroborada pela inclusão de uma lógica gerencial empresarial como medida de eficiência e eficácia da escola. 
Quando se trata da "nova organização laboral de ensino", cuida-se de um processo de reestruturação produtiva assolado no Sistema Educacional Brasileiro, marcado por uma forte ideologia de mercado, em que a função docente tornou-se uma mercadoria.

Em atenção as recentes tranformações no setor educacional, em um segundo momento, este artigo centra seus objetivos em algumas indagações, quais sejam, se a nova organização laboral tem contribuído para a desvalorização do papel social do professor, bem como de que maneira é compreendida a flexibilização do trabalho docente e quais os seus efeitos na atividade laboral e na qualidade do ensino.

Ademais, em um Estado Democrático de Direito, tal como é o Brasil, prima-se pela proteção da dignidade da pessoa humana. Este princípio basilar é estendido quando do ambiente de trabalho digno ao exercício pleno da profissão docente. O processo de desvalorização do trabalho do professor não pode ser compreendido somente no âmbito econômico, sendo que se vislumbra nos fenômenos da "desprofissionalização” do trabalho docente, “comunitarismo”, “privatização” do ensino e a consequente perda da qualidade da educação.

Sendo assim, quais são as políticas públicas existentes e voltadas para a valorização do trabalho docente no Brasil? Serão elas eficientes no atual cenário brasileiro?

Insta ressaltar que o corpo legislativo brasileiro está impregnado de normas e princípios que propugnam uma educação com base na valorização dos profissionais do ensino, bem como um padrão de qualidade educacional elevado, com a finalidade de garantir o exercício do direito social à educação.

Por meio da análise dos fenômenos que compõem o atual cenário do Brasil, pretende-se perceber o grau de comprometimento do Poder Público para com a efetivação dessas normas, visto que foram elaboradas com fincas no princípio da dignidade da pessoa humana, quando da sua extensão ao meio ambiente de trabalho docente.

Por final, em atenção à desvalorização do papel do professor percebida no cenário social brasileiro, junta-se esforços para a elaboração de propostas em contributo a um processo de valorização do professor. Cuida-se de propostas que não surtirão efeitos a curto prazo, visto que grande é a necessidade de comprometimento do Poder Público no auxílio contra a erradicação da precarização laboral docente. 


\section{NORMAS DE PROTEÇÃO AO TRABALHADOR DOCENTE}

Na história da educação brasileira, inegável é a essencialidade do papel social e pedagógico do profissional de ensino. Porém, no desencadear do constitucionalismo brasileiro não havia fortes sinais de valorização da educação da profissão docente, visto que embora de cunho essencial, não lhe era oferecido garantias constitucionais para avalorização do trabalho digno e dignidade no ambiente laboral.

Recentemente, na Constituição de 1988, bem como na Lei de Diretrizes e Bases da Educação, em 1996, foi contemplado nos seus textos princípios e normas para a valorização dos professores. Embora não possamos negar o avanço legislativo no que condiz com a proteção e valorização do profissional de ensino, na prática educacional esses avanços tem sido insuficientes, eis que apesar da sua grande responsabilidade pedagógica e social, os educadores não são tratados de forma digna na sociedade brasileira.

O cenário educacional brasileiro impregnado pela desvalorização social do trabalho dos profissionais do saber retrata professores com sérios problemas de saúde, tais como a síndrome deburnout ${ }^{1}$, depressão, síndrome do pânico, dentre outras diversas doenças emocionais e decorrentes do exercício da função docente, intensificado pela precariedade no ambiente de trabalho, salários incompatíveis com a complexidade do magistério, resultando na própria precariedade do sistema de ensino e na falta de eficácia das leis de proteção ao trabalhador docente.

A formação de professores constitui elemento fundamental para atingir os objetivos visados pela educação, uma vez que é o professor que, em sua prática, operacionaliza as grandes linhas propostas pelas reformas educacionais. Estas, por sua vez, devem estar adaptadas à realidade da sociedade, em determinados contextos históricos. No Brasil, porém, nem

\footnotetext{
${ }^{1}$ A síndrome de burnout, conforme Nunes e Teixeira, pode ser definida como "um conjunto de respostas às situações estressantes próprias do trabalho, cuja especificidade reside na necessidade de interação e cuidado constante com outras pessoas, no exercício das atividades profissionais”. Estas respostas podem ser psicossomáticas, tais como fadiga crônica, dor de cabeça constante, alterações do sono, perda do peso, dores musculares, alterações gastrointestinais, comportamentais (incapacidade de relaxar, superficialidade no contato com as pessoas, condutas violentas), alterações emocionais (distanciamento afetivo, tédio, impaciência, frustação, dificuldade de concentração, sentimentos depressivos. FACCI, Marilda Gonçalves Dias. Valorização ou esvaziamento do professor?: um estudo crítico comparativo da teoria do professor reflexivo, do construtivismo e da psicologia vigotskiana. Campinas, SP: Autores Associados, 2004. p. 31.
} 
sempre se respeitou essa vinculação da essencialidade da função docente entre a escola e sociedade (VIEIRA, 2012).

Além de consagrar os “direitos e deveres individuais e coletivos”, a Constituição Federal de 1988 abre uma capítulo para definir os direitos sociais, que vinham sendo, desde 1934, inseridos no capítulo da "Ordem econômica e social”. Institui, desta forma o Estado Democrático de Direito. Especificamente no capítulo II, art. $6^{\circ}$, a educação está prevista entre o rol dos direitos sociais. A implementação de tais direitos ocorre mediante políticas públicas que buscam concretizar certas prerrogativas individuais e/ou coletivas, destinadas a reduzir as desigualdades sociais existentes e a garantir uma existência humana digna (NOVELINO, 2011).

$\mathrm{O}$ direito à educação, expresso no art. $6^{\circ}$ e explicitado nos artigos 205 a 214 são de eficácia limitada, no qual necessitam de atuação do legislador infraconstitucional para que se torne plenamente eficaz.

Em uma democracia, deve-se primar pela segurança dos direitos fundamentais, bem como zelar pelos direitos que constituem o Princípio da Dignidade Humana, talvez o pilar mais sólido de um Estado Democrático de Direito. É o que sustenta José Celso de Mello Filho (MELLO FILHO, 1986, p 533) A educação é um dos pilares que sustentam a garantia da dignidade da pessoa humana:

[...] é mais compreensivo e abrangente que o da mera instrução. A educação objetiva propiciar a formação necessária ao desenvolvimento das aptidões, das potencialidades e da personalidade no educando. $\mathrm{O}$ processo educacional tem por meta: (a) qualificar o educando para o trabalho; e (b) prepará-lo para o exercício consciente da cidadania. O acesso à educação é uma das formas de realização concreta do ideal democrático.

Desta feita, a constituição de 1988, também denominada de Carta Social, contemplou em seu texto princípios e normas de valorização dos profissionais de ensino, eis que notória a essencialidade da função pedagógica e social dos professores no que condiz a eficácia e plenitude do direito à educação, considerada como atributo da pessoa humana. Neste mesmo sentido nos ensina a doutrina de José Afonso da Silva (SILVA, 2009):

[...] a educação como processo de reconstrução da experiência é um atributo da pessoa humana, e por isso, tem que ser comum a todos. É 
essa concepção que a Constituição agasalha nos arts. 205 a 214, quando declara que ela é um direito de todos e dever do Estado.

Vítor Henrique Paro (2012, apud PADILHA), ao tratar da qualidade da força de trabalho na área da educação, afirmou ser o corpo docente o "elemento mais importante que a escola pode oferecer na realização do trabalho de efetiva qualidade [...]”. Essa citada importância do elemento humano está expressa no texto da Constituição Federal vigente. A Lei Maior, na parte que trata da educação, estabelece, como um dos princípios que devem reger as atividades de ensino, a valorização dos diversos profissionais da área da educação, conforme artigo 206, inciso V.

De uma forma genérica, aplicável a todos os trabalhadores, no qual se insere o trabalho docente, a Constituição Federal vigente, no capítulo II, dos Direitos Sociais, precisamente no art. $7^{\circ}$, elenca um rol de direitos em contribuição à melhoria da condição social dos trabalhadores brasileiros.

Notória a essencialidade do professor quanto à promoção da educação de boa qualidade, eis que a Lei Maior, conforme anteriormente analisada, na seção que trata da educação, estabelece, como um dos princípios que devem reger as atividades de ensino, a valorização dos diversos profissionais da área da educação, sendo expressamente assegurada a importância do elemento humano na qualidade do ensino (artigo 206, inciso V, CF).

Embora a legislação trabalhista vigente não conceitue a figura do professor, apenas se refere ao exercício do magistério, o professor é caracterizado como o principal agente dos propósitos da educação:

[...] professor é o trabalhador que ensina que tem como tarefa ou missão a transmissão de conhecimentos. O professor é o principal agente dos propósitos da educação, por executar as atividades que visam a desenvolver as capacidades intelectuais, psíquicas e morais da pessoa humana, englobando práticas individuais e estatais ou institucionais (PADILHA, 2012).

Desta feita, a Consolidação das Leis do Trabalho, Decreto-lei n 5.452 , de $1^{\circ}$ de maio de 1943 , no título das normas especiais de tutela do trabalho, prevê regras específicas aos professores, conforme se observa dos artigos 317 ao 324.

Em análise aos dispositivos infraconstitucionais abarcados no título das normais especiais da CLT, especificamente na seção XII, dos 
professores, verifica-se que a legislação trata do exercício do magistério. São consideradas funções de magistério:

[...] as exercidas por professores e especialistas em educação no desempenho de atividades educativas, quando exercidas em estabelecimentos de educação básica em seus diversos níveis e modalidades, incluídas, além do exercício da docência, as de direção de unidade escolar e as de coordenação e assessoramento pedagógico (CARRION, 2008).

Um dos aspectos relevantes contidos na CLT é condizente a carga horária a que estão sujeitos os professores, no qual, em atenção ao artigo 318 , não poderá ministrar mais de quatro aulas consecutivas ${ }^{2}$, nem seis intercaladas num mesmo estabelecimento, porém nada impede que o professor trabalhe em mais de um estabelecimento de ensino. A atividade do professor não está adstrita apenas a ministrar as aulas:

[...] o professor tem de prepará-las em casa, o que demanda tempo, corrigir provas e trabalhos, atividades que a lei não determina pagamento ao professor. Atividades extraclasse, prestadas na casa do professor, como de correção de provas e trabalhos, preparação de aulas, não são consideradas horas extras, até porque não há fiscalização do empregador nesse sentido e a atividade é externa. Daí por que nas normas coletivas se colocar outro pagamento chamado hora-atividade, que tem por fim remunerar a preparação de aulas do professor (MARTINS, 2009).

Outra regra relevante merecedora de tal análise é a contida no art. 320 da CLT, no qual “a remuneração dos professores será fixada pelo número de aulas semanais, na conformidade de horários” (BRASIL, 2011).

Sobre o mencionado dispositivo, afirma-se que o adicional noturno está assim remunerado com a redução do horário. No entanto, há entendimento diverso, como por exemplo, o de Sergio Pinto Martins, no qual sustenta que é a simples redução da hora noturna, como previsto na CLT, o que é inclusive mais benéfico ao professor, mas não o pagamento de adicional noturno (MARTINS, 2009).

\footnotetext{
${ }^{2}$ A Portaria $n^{\circ}$ 204/45 do Ministério da Educação e Cultura estabelece que a hora-aula do professor durante o dia é de 50 minutos e de 40 minutos à noite, nos estabelecimentos de ensino superior ou médio; nos demais a hora-aula é de 60 minutos.
} 
Por fim, resta o exame do art. 323 da CLT, eis que trata da questão salarial dos professores. O texto da lei utiliza a expressão remuneração “condigna”, porém o conceito de dignidade inserido neste contexto é de uma grande imprecisão. Conforme adiante será analisado, o salário dos professores tem sido uma das principais formas de revelação da precariedade do trabalho docente, eis que mal remunerados em malefício da complexidade que implica a função do magistério, bem como a importância da profissão.

Vicente Carrion considera o art. 323 como "letra morta”. (CARRION, 2008). Na concepção de Sérgio Pinto Martins, esse artigo é praticamente inútil, o qual deveria ser revogado:

O conceito de remuneração condigna é muito ambíguo e depende também daquilo que o mercado estabelece e de acordo com as normas coletivas da categoria. Se esse dispositivo fosse aplicado à risca, muitas escolas já teriam fechado, pois, de modo geral, o professor ganha mal e, para ter um salário melhor, tem de ministrar aulas em várias escolas ao mesmo tempo, trabalhando em três períodos (MARTINS, 2009).

Apesar da importância da função docente no contexto da administração do ensino e a previsão normativa de princípios que preveem a valorização dos profissionais da educação, a necessidade de condições adequadas de trabalho e de remuneração condigna dos educadores, a realidade brasileira tem apresentado um quadro geral de precariedade das condições de trabalho, de desqualificação do trabalhado do docente, de aviltamento do salário, de desrespeito aos direitos trabalhistas básicos do professor empregado (PADILHA, 2012).

Sendo assim, há a necessidade de um intenso trabalho de aclaramento quanto aos principais direitos especiais conferidos ao professor empregado pela legislação trabalhista, consistente, principalmente, na observação da regularização dos contratos de trabalho, como também concessão de uma remuneração condigna ao trabalhado docente, sendo que também há a necessidade de conscientização quanto à importância do regular cumprimento destes preceitos.

Em uma sociedade cujos valores são pautados em ideais democráticos, o exercício legislativo está atrelado ao princípio da necessidade, eis que, embora a lei revele um papel de suma importância no Estado de Direito, 
são elaboradas em virtude da indigência social, bem como para a garantia de uma vida justa e digna que almejam todos os cidadãos.

Miguel Reale salienta que toda regra jurídica, além de eficácia e validade, deve ter um fundamento:

O Direito, consoante outra lição de Stambmler, deve sempre, “uma tentativa de Direito justo", por visar à realização de valores ou fins essenciais ao homem e à coletividade. [...] É a razão de ser da norma, ou ration júris. Impossível é conceber-se uma regra jurídica desvinculada da finalidade que legitima sua vigência e eficácia (REALE, 2000).

Desta feita, as normas especiais de proteção ao trabalho docente são vinculadas a um fundamento e finalidade, eis que de nada valeriam as normas se não fosse necessária a sua legitimação para a garantia do exercício virtuoso da atividade docente.

Não restam dúvidas de que o principal patrimônio do Sistema de Educação Brasileiro é a capacidade docente (intelectual, técnica ou profissional) para desenvolver projetos, pesquisas e oportunizar a todos os cidadãos o direito social à educação, previsto no art. $6^{\circ}$ da Constituição Federal vigente.

Sendo assim, qual seria o fundamento das normas especiais de proteção ao trabalho docente, e qual a sua real finalidade? Há respostas para essas indagações, porém elas estão dispersas nos ideais democráticos que regem a sociedade brasileira.

Conforme analisado anteriormente, a Educação é um dos direitos fundamentais e essenciais ao homem, visto que é o principal caminho para o progresso e garantia de liberdade dos cidadãos, um dever do Estado e direito de todos.

De suma importância asseverar que o professor é o mecanismo que promove a atividade educacional, de modo que extremamente necessário à finalidade da educação. Ademais, todo trabalhador brasileiro possui o direito do exercício de seu labor seguro, livre, submetido a um meio ambiente de trabalho equilibrado, remunerado de acordo com suas particularidades, o que não se difere em relação à atividade docente.

As normas especiais de proteção ao trabalho do professor possuem os seus fundamentos nas próprias diretrizes dos Direito Humanos, tão atrelados ao Direito do Trabalho: 
O Direito do Trabalho corresponde à dimensão social mais significativa dos Direitos Humanos, ao lado do Direito Previdenciário. É por meio desses ramos jurídicos que os Direitos Humanos ganham maior espaço de evolução, ultrapassando fronteiras originais, vinculadas basicamente à dimensão da liberdade e intangilibidade física e psíquica da pessoa humana (DELGADO, 2012).

Cumpre salientar que a finalidade da legislação não é oferecer direitos especiais a determinada função laborativa, mas sim compreender as diversas especialidades de cada profissão e garantir o pleno exercício da atividade, no presente caso, a atividade docente.

\section{REESTRUTURAÇÃO “EMPRESARIAL” E TRABALHO DOCENTE}

Na busca pela adequação da atividade docente ao imperativo da globalização, o campo educacional brasileiro foi cenário de reformas que tentaram realocar os professores, vistos não apenas como agentes culturais, mas também, e essencialmente, como agentes políticos.

As reformas educacionais brasileiras dos anos 1960 tiveram como escopo ampliar o acesso à escolaridade, compreendida como meio mais eficaz e seguro para a mobilidade social e para a erradicação das desigualdades sociais, no interior da vigência do ideário nacional de desenvolvimento, representando uma tentativa de adequação às exigências do padrão de acumulação fordista (SANT’ANA, 2010).

A situação de trabalho precário teve seu início associado a mudanças percebidas no mundo do trabalho ocorridas por volta da década de 1970 . No campo educacional, o neoliberalismo representou o estabelecimento de reordenações nos sistemas educacionais “a partir de uma redefinição do papel do Estado na sua relação com a educação, e, de outro lado, a inclusão de uma lógica gerencial empresarial como medida de eficiência e eficácia da escola” (MANCEBO apud SANT’ANA, 2010).

Nos anos 1990, as reformas educacionais trouxeram novos objetivos para a escola, quais sejam, os de promover a educação para a equidade social e formar indivíduos para a empregabilidade. A reestruturação produtiva e as mudanças no mundo do trabalho, ascensão do neoliberalismo e a reconfiguração do papel do Estado ganharam materialidade expressiva 
quando do interior do processo de globalização da economia, tendo alcance significativo no campo da educação escolar (SANT’ANA, 2010).

Dessa maneira, faz-se necessário posicionar a questão da precarização do exercício da função docente nas mudanças ocorridas nos últimos trinta anos no mundo do trabalho. Antônio Bosi salienta que a "precarização do trabalho não pode ser resumida a um processo exclusivamente econômico, mas tem implicações principalmente de natureza social, cultural e política à medida que interfere na auto percepção que os docentes tem de si” (BOSI, 2001).

É possível destacar a sensação de um “mal-estar docente” impregnada na classe trabalhadora comprometida com o ensino:

A sensação de mal-estar, de desânimo e mesmo de descontentamento com o próprio trabalho pode ser representada pelos sentimentos que os professores tem diante das circunstâncias que o próprio processo histórico produziu em termos de educação, tais como: desmotivação pessoal e, muitas vezes, abandono da própria profissão; insatisfação profissional, percebida por meio de pouco investimentos e indisposição na busca de aperfeiçoamento; esgotamento e estresse, como consequência do acúmulo de tensões; depressão; ausência de uma reflexão crítica sobre a ação profissional e outras reações que permeiam a prática educativa e que acabam, em vários momentos, provocando um sentimento de auto depreciação (ESTEVE apud FACCI, 2004).

Este "mal-estar docente" decorre de fatores que se circunscrevem no âmbito da prática docente, bem como também são referentes às condições ambientais, ao contexto em que se exerce a docência, tais como:

Modificação no papel do professor e dos agentes tradicionais de socialização(pais, família): os professores acabam tendo que assumir papéis que não correspondem somente ao ato de ensinar; contestação e contradições na função docente: as transformações da sociedade exigem do professore novas posturas, ele tem que desempenhar papéis contraditórios e não há consenso sobre como deve ser o professor; modificação do apoio do contexto social: pouca valorização social do trabalho, baixo salário e status inferior com relação a outros profissionais com a mesma titulação; mudanças no objetivo do sistema de ensino e no avanço do conhecimento: a escola já não serve de "trampolim” para o sucesso e não é mais garantia de emprego e, além disso, na sociedade, 
está havendo um avanço muito grande em relação ao saber e os professores tem que renovar seus conhecimentos continuamente para não se exporem ao ridículo; a imagem do professor: contradição entre uma imagem idealizada e uma situação real do que é ser professor; recursos materiais e condições de trabalho: falta de materiais didáticos, debilidade de estruturas físicas adequadas ao ensino e também de formas de funcionamento da instituição (horários, reuniões, avaliações); violência nas instituições escolares: depredação, roubo de materiais da escola, agressão (física e/ou verbal) contra professores e alunos; esgotamento docente e acúmulo de exigências sobre o professor: síndrome deburnou(FACCI, 2004).

O trabalho do professor é na forma em que se apresenta hoje, “um trabalho não manual, assalariado, num setor não produtivo, embora socialmente útil, da atividade humana” (PESSANHA, 1997). Sendo assim, haja vista que o trabalho docente não tem como fim a produção de maisvalia, a lógica que o enseja diferencia-se daquela presente nos empreendimentos lucrativos (SANT'ANA, 2010).

Porém, a questão é que a ideologia de mercado assolou a independência educacional, visto que na sociedade do conhecimento, a educação é o fator crítico da criação de riquezas. "No Brasil, o setor educacional soma aproximadamente $14 \%$ do PIB, mais do que os setores elétricos, de petróleo e de telecomunicações juntos” (GURGEL, 2013).

A tensão gerada na profissão docente apenas contribui para com a exaustão do sistema de ensino. Insta salientar que, a reestruturação das atividades do ensino que corrobora para com o ideal de transformação produtiva com equidade, acaba por refrear uma das grandes conquistas prevista no artigo 206 da Constituição Federal, no qual prevê um ensino com base no princípio da valorização dos profissionais da educação escolar. Uma mera garantia que está muito distante de ser implementada no cotidiano dos profissionais do saber.

Embora a legislação constitucional e as leis infraconstitucionais emoldurarem a educação como um direito fundamental, o Estado, por meio dos processos de flexibilização e mercantilização do ensino, terceirizou seu compromisso de dever para com a educação, formando um processo, já com grande intensidade no cenário brasileiro, conhecido como "privatização do ensino". 
Este fenômeno, fruto da reestruturação das atividades de ensino opera em desfavor da valorização dos profissionais do saber, no qual implica em notória falta de respeito aos princípios elencados no artigo 206 da Constituição federal de 1988.

Os professores, vistos como os agentes internos do fenômeno da privatização do ensino ficam sujeitos à ideologia de mercado, sendo que a mercantilização da educação torna o corpo docente uma figura mercantil.

A perda da autonomia de ensino é marca deste processo, sendo que os educadores tem que adequar a sua capacidade criativa aos desígnios do empresariamento do processo ensino-aprendizagem:

O professor é "convidado" a ser "criativo" nos estreitos limites colocados pelas regras da educação, definidas nos gabinetes dos tecnoburocratas e "especialistas” da área. Essa “criatividade” também é bastante solicitada para fazer funcionar as instituições educacionais com parcos recursos materiais e falta crônica de profissionais (SANT’ANA, 2010).

Por meio do processo de reestruturação das atividades docentes, a qual se insere o fenômeno da privatização do ensino, a educação transformou-se em verdadeira mercadoria, com o fim de atendimento ao mercado:

A defesa da ampliação do campo educacional como esfera de ganhos derivados e a ideia de um sistema de educação superior tão hierarquizado quanto é a sociedade encontram, no final do século, condições mais favoráveis (PINTO, 2007).

A transformação da educação em mercadoria implica na desvalorização social do papel do professor. Assim, o trabalho dos profissionais do saber fica completamente atrelado ao atendimento de mercado, com sua capacidade criativa e atuação restrita. Perdem a qualidade de função essencial ao ensino para figurarem como meros operadores da educação.

Esta flexibilização é compreendida pela desregulamentação da legislação trabalhista, ou pelo menos, a sua ineficiência. O aumento dos contratos temporários, arrocho salarial, inadequação ou até mesmo ausência de planos e cargos, a queda nas taxas de sindicalização, redução e ineficácia 
de greves, a perda de garantias trabalhistas e previdenciárias oriunda dos processos de reforma do Aparelho de Estado exemplificam, em parte, a flexibilização da atividade docente, como também tem tornado cada vez mais agudo o quadro de instabilidade e precariedade do emprego no magistério (OLIVEIRA, 2004).

Por outro lado, a flexibilização do exercício laborativo educacional vai além das da supressão das garantias dos contratos de trabalho e das legislações social e trabalhista. Abarca, também, os fenômenos da “desprofissiolização”, “comunitarismo” e “intensificação” do trabalho docente.

A desprofissionalização é identificada com a inserção de novas funções nas atividades educadoras:

A escola passa a assumir novas funções que trazem diversificadas exigências, como por exemplo, suprir necessidades de lazer e cultura da região onde se situa, realizar ações de educação em saúde, dentre outras, desdobrando-se para construir propostas como "escola aberta" aos finais de semana, realização de projetos em parceria com iniciativa privada e comunidade local, dentre outros. Esse cenário traz um sentimento de desprofissionalização e de perda de identidade profissional ao professor, além de representar a desqualificação do seu trabalho (SANT’ANA, 2010).

Essas novas exigências contribuem para um sentimento de desprofissionalização, da perda da identidade profissional, da constatação de que ensinar, às vezes, não é o mais importante:

O professor diante das variadas funções que a escola pública assume, tem de responder a exigências que estão além de sua formação. Muitas vezes esses profissionais são obrigados a desempenhar funções de agente público, assistente social, enfermeiro, psicólogo, entre outras (OLIVEIRA, 2004).

A situação é reforçada pelas estratégias de gestão que apelam ao comunitarismo e voluntariado, na promoção de uma educação para todos:

A escola é transformada em unidade do sistema - daí a "performatividade escolar" como parâmetro de eficácia e produção de resultados - e introduzse uma lógica gerencial pautada pelos conceitos de produtividade, 
eficácia, excelência e eficiência. Há, ainda, o apelo ao voluntarismo e aos comunitarismo como forma de suprir necessidades das quais o Estado se libera (OLIVEIRA apud SANT’ANA, 2010).

O contexto das reformas educacionais ensejado pelos movimentos que propugnavam a gestão democrática é marcado pelo aumento da partição da comunidade na escola:

Uma gestão democrática da educação, que reconhecesse a escola como espaço de política e trabalho, era buscada nos emblemas de autonomia administrativa, financeira e pedagógica, na participação da comunidade nos desígnios da escola (elaboração dos projetos pedagógicos e definição dos calendários) e na criação de instâncias mais democráticas de gestão (eleição de diretores e constituição dos colegiados). Tudo isso conjugado à luta pelo reconhecimento profissional desses trabalhadores (OLIVEIRA, 2004).

Esse movimento, ao mesmo tempo em que democratiza a escola, proporcionando ganhos para a população em geral e para os trabalhadores da educação em especial, também representa maior ameaça para esses profissionais no que se refere às supostas garantias de algumas particularidades da função docente:

Abrir os conteúdos e as práticas do seu fazer cotidiano é muitas vezes tomado pelos professores como um sentimento de desprofissionalização. A ideia de que o que se faz na escola não é assunto de especialista, não exige um conhecimento específico, e, portanto, pode ser discutido por leigos, e as constantes campanhas em defesa da escola pública que apelam para o voluntariado contribuem para um sentimento generalizado de que o profissionalismo não é o mais importante no contexto escolar (OLIVEIRA, 2004).

Alguns projetos, como por exemplo, o "Projeto Amigos da Escola Todos pela Educação”, lançado pela Rede Globo de Televisão, em 1999, são ações de incentivo para o desenvolvimento de ações de voluntariado individual e de parcerias com a escola. Porém, questionáveis são as formas de estímulo para adesão a esse tipo de programa, visto que incentiva os cidadãos a entrarem no meio escolar, sem qualquer tipo de preparo para 
lidar com os alunos, bem como se o trabalho de ensino fosse algo secular e que qualquer pessoa poderia executá-lo.

Abaixo, estão elencadas algumas das consequências de uma política de participação da comunidade no seio escolar sem comprometimento para com a qualidade de ensino e respeito do princípio constitucional de valorização do profissional docente:

Desresponsabilização do Estado na medida em que, por meio da ação voluntária, se transfere à sociedade a responsabilidade pela manutenção das escolas; a desvalorização dos profissionais da educação, uma vez que qualquer cidadão poderia substituí-los; a criação de um ambiente propício para justificar a redução dos investimentos estatais, uma vez que existem pessoas com boa vontade para assumirem as obrigações do Estado; o incentivo à participação de voluntários em áreas que precisam de preparo e formação específica, tais como reforço escolar, Educação Física e Arte; as consequências negativas para a educação dos alunos na medida em que seriam "formados" por pessoas que não foram preparadas para esse fim (CALDERÓN, 2007).

A proposta de democratização do ensino embrenhada no cenário brasileiro, na realidade condiz com uma forma de “demissão” do Estado em relação as políticas públicas que deveriam auxiliar na infraestrutura do trabalho docente. A ideia de democratização deveria aproximar a comunidade do meio escolar, garantindo educação plena a todos os cidadãos, porém o que se tem observado é uma aproximação da comunidade ao corpo docente para fins de caridade e filantropia, como se o Estado abdica-se de seu dever essencial de mantenedor da educação e repassassa esta função à comunidade, já desprovida de cuidados.

A perda do status da profissão docente, alavancada pela diminuição dos rendimentos e pelos processos de funcionarização e assalariamento, torneia os caminhos referente à intensificação das atividades dos professores:

O trabalho docente também se intensifica com o aumento do númerode alunos por turma e se amplia na medida em que não é mais definido como aquele que acontece apenas em sala de aula: também cabe ao professore a gestão da escola, sua dedicação ao planejamento, à elaboração de projetos, à discussão coletiva do currículo e da avaliação. Essa participação na gestão da escola, longe de significar o atendimento de antigas 
reivindicações dos movimentos de professores no sentido de antigas reivindicações dos movimentos de professores no sentido da democratização da organização do trabalho, na medida em que não vem acompanhada de autonomia, ou seja, de condição de interferir na concepção e na organização de seu trabalho (SANT’ANA, 2010).

Nesse sentido, o processo de intensificação pode ser sintetizado como um processo que:

Conduz à redução do tempo para descanso na jornada de trabalho; implica a falta de tempo para atualização em alguns campos e requalificação em certas habilidades necessárias; implica uma sensação crônica e persistente de sobrecarga de trabalho que sempre parece estar aumentando, mais e mais tem para ser feito e menos tempo existe para fazer o que deve ser feito. Isso reduz áreas de decisão pessoal, inibe envolvimento e controle sobre planejamento de longo prazo, aumentando a dependência a materiais externos e a técnicos especialistas também externos ao trabalho, o que provoca um aumento da separação entre concepção e execução, entre planejamento e desenvolvimento; conduz à redução na qualidade do tempo, pois para se "ganhar" tempo somente o "essencial” é realizado. Isso aumenta o isolamento, reduzindo as chances de interação (já que a participação motiva comportamento crítico) e limitando as possibilidades de reflexão conjunta. Habilidades coletivas de trabalho são perdidas ou reduzidas enquanto habilidades de gerência são incrementadas; produz uma imposição e incremento diversificado de especialistas para dar cobertura a deficiências pessoais; introduz soluções técnicas simplificadas (tecnologias) para as mudanças curriculares a fim de compensar o reduzido tempo de preparo (planejamento); frequentemente os processos de intensificação são mal interpretados como sendo uma forma de profissionalização e muitas vezes é voluntariamente apoiada e confundida como profissionalismo (HYPOLITO, 2009).

Segundo dados da APEOESP - Associação dos Professores do Estado de São Paulo, no Brasil observam-se um grande número de professores readaptados, afastados temporária ou permanentemente para as atividades administrativas, sendo afetados por uma ou algumas doenças da área da psiquiatria, neurologia, otorrinolaringologia, reumatologia ou mesmo professores que se mantém em sucessivas licenças de saúde por razões diversas (APEOESP, 2013). 
O cotidiano do professor e as condições de trabalho a ele fornecidas têm sido citados como grandes causadores de afastamento dos mesmos da sala de aula:

Os afastamentos por problemas psicológicos tem sido os maiores causadores de solicitações de licenças médicas pelos professores. O ritmo intenso de trabalho, suas longas jornadas de trabalho, a tensão do ambiente escolar, o acúmulo de atividades do professor bem como a indisciplina dos alunos e sua dificuldade de aprendizagem, tem sido apontados como uma das fontes geradoras de doenças para os docentes (COSTA, 2007).

O professor é elemento fundamental para o bom funcionamento do sistema escolar. Todavia os fenômenos atrelados a precarização do trabalho docente contribuir para uma perda significativa na qualidade do processo ensino-aprendizagem. Ademais, impossibilita o exercício de um trabalho nos moldes propugnado pela Constituição Federal, em atenção ao princípio da valorização do trabalho humano.

\section{AÇÕES DE ESTADO E VALORIZAÇÃO DO MEIO AMBIENTE DOCENTE}

Em meio a tantas garantias normativas, como tem sido a investida das ações de Estado que visam efetivamente a valorização do trabalho humano, em especial a valorização do profissional docente? São estas garantias constitucionais e infraconstitucionais válidas quando percebidas no cenário das condições laborativas atuais?

Estas indagações deveriam ser tranquilamente respondidas, tendo em vista que todo ordenamento jurídico brasileiro é baseado em previsões normativas que zelam pela valorização do trabalho humano, o que abrange o trabalho dos professores.

Entretanto, não é o que se tem observado no cotidiano político brasileiro, quando observadas as políticas públicas de promoção da valorização do profissional docente.

Primeiramente, cumpre salientar que as ações de Estado devem promover a eficácia das normas de valorização do trabalho humano, eis que de nada vale um instrumento normativo se este, quando da sua aplicação, se desvincula de seus princípios, tonando toda a estrutura normativa sem 
força na busca pela implementação das garantias de um trabalho digno. Ressalta-se que a eficácia das normas é condição de validade:

[...] desde que uma norma isolada e toda uma ordem normativa perdem sua validade, deixam de valer, quando elas perdem sua eficácia, ou a possibilidade de uma eficácia; tanto quanto interessem normas gerais, se habitualmente cessam de ser cumpridas e se não cumpridas deixam de ser aplicadas (KELSEN, 1986).

Na realidade, o que se depreende do contexto social brasileiro, bem como das políticas públicas supostamente implementadas é que o Estado está completamente desvinculado da obrigação de atuar, nem ao menos em colaboração, com a promoção da eficácia das normas e princípios que propugnam a valorização do profissional docente.

Muito pelo contrário, uma vez que perfeitamente nítido o descaso estatal para com a educação, principalmente para a com a carreira do professorado brasileiro.

É fácil estabelecer normas de valorização ao trabalho docente, porém sem se preocupar com as suas implementações:

Em cada período histórico os legisladores constituintes, de regra, incorporam nas Leis Fundamentais aquilo que no período correspondente se consagrou como a mais generosa expressão do ideário da época. Fazemno, muitas vezes, com simples propósito retórico ou porque não se podem lavar de consigná-los. Mas animados de reta intenção ou servindo-se disto como blandicioso meio de atrair sustentação política ou de esquivar-se à coima de retrógradas, o certo é que geralmente as Cartas Constitucionais estampam versículos prestigiadores dos mais nobres objetivos sociais e humanitários que integram o ideário avalizado pela cultura da época (MELLO, 2010).

As possibilidades de efetivação do direito ao trabalho digno, em especial o trabalho docente, depende de políticas públicas que colaborem para o exercício do trabalho em condições decentes, não de ações estatais que demonstrem o caráter antidemocrático das ações do Estado.

O Poder Público Brasileiro, na realidade, preocupa-se em manter a imagem de um país onde há educação acessível a todos, porém sem que tenha que dispor de dinheiro para isso, o que prejudica o profissional docente. 
Denota-se que o legislador brasileiro não se atentou para com a efetivação das garantias da dignidade da pessoa humana, quando inserida no âmbito do trabalho.

Nem tampouco o Estado desenvolve ações que procuram proporcionar a adequação das condições de labor docente em meio a um processo de reestruturação produtiva marcada pela intensificação do trabalho, contrapondo as reais necessidades de valorização do profissional da educação.

Desta feita, com a carência de políticas públicas de valorização do profissional docente, observa-se o total descomprometimento para com os problemas sociais que envolvem a função e carreira dos professores, sendo corroborado pela ausência de ações estatais que deveriam zelar pela eficácia das normas e princípios de valorização do trabalho e dignidade da pessoa humana, também quando da sua extensão de proteção ao labor docente.

A segurança jurídica, limitada à acepção formal, é a previsibilidade e certeza do direito, sendo que, em atenção à força normativa da Constituição, os princípios jurídicos constitucionais são dotados também de eficácia positiva (IBRAHIM, 2012).

Há a necessidade de incentivos que venham a efetivar os mandamentos legais, bem como o Poder Público deve proporcionar a implementação dos direitos constitucionais, de modo que os objetivos da Constituição não sejam perdidos.

Ao professor é assegurado, assim como qualquer outra profissão, o meio ambiente de trabalho equilibrado, sendo este um direito fundamental, eis que diz respeito à dignidade da pessoa humana.

Primeiramente, cumpre salientar que quando a Constituição Federal de 1998, em seu artigo 225, caput, refere-se ao "direito ao meio ambiente ecologicamente equilibrado” como um "bem”, destacando suas peculiaridades, quais sejam, ser de "uso comum do povo" e "essencial à sadia qualidade de vida”, remete-se a essencialidade do fundamento da dignidade da pessoa humana. Desta feita, o direito a um meio ambiente equilibrado é um direito fundamental.

Embora a Carta Magna não tenha sido expressa quando da amplitude do termo "meio ambiente”, compreende-se que este abrange todos os aspectos da inter-relação indivíduo e ambiente. Sendo assim, ao reportar-se ao meio ambiente de trabalho, vislumbra-se um ecossistema que envolve as interrelações da força de trabalho com os meios e formas de produção e serviços, bem como a afetação gerada em seu meio: 
O meio ambiente é unitário e sua classificação se faz, apenas, em decorrência de seus múltiplos aspectos e atendendo a um escopo meramente didático, inclusive para que se compreenda integralmente o âmbito da tutela dos bens ambientais. Quando a Constituição Federal, em seu art. 225, fala em meio ambiente ecologicamente equilibrado, está mencionando todos os aspectos do meio ambiente. E, ao dispor, ainda, que o homem para encontrar uma sadia qualidade de vida necessita viver nesse ambiente ecologicamente equilibrado, tornou obrigatória também a proteção do ambiente no qual o homem, normalmente, passa a maior parte de sua vida produtiva, qual seja, o do trabalho (PADILHA, 2002).

As relações inerentes ao trabalho estão sob a influência e afetação do meio ambiente. Tratar da precarização do trabalho docente sem mencionar alguns aspectos do habitat laboral, não é apropriado, visto que a inter-relação entre professores e as condições do meio ambiente em que se encontram pode ser considerada como uma das principais causas de contribuição ao desgaste docente, bem como suas implicações afetam diretamente a saúde dos professores brasileiros.

O que se observa na realidade é que a atividade do professor brasileiro está impregnada pelo descaso estatal, visto que, nem ao menos uma estrutura digna em contribuição ao meio ambiente de trabalho equilibrado está dentre as prioridades das políticas públicas. Muito pelo contrário, a falta de infraestrutura, tal como salas de aulas superlotadas, falta de materiais didáticos, falta de proteção ao docente no seu local de trabalho, as condições psíquicas a que estão submetidos, o que implica no desrespeito à sadia qualidade de vida, evidencia a precarização do ambiente de trabalho do docente.

A saúde do trabalhador tem relação íntima com o seu ambiente de trabalho, sendo oportuno salientar, ainda, que a Convenção $\mathrm{n}^{0} 155$ da Organização Internacional do Trabalho fornece a seguinte abrangência do termo saúde:

O termo "saúde" com relação ao trabalho abrange não só a ausência de afecções ou de doenças, mas também elementos físicos e mentais que afetam a saúde e estão intimamente relacionados com a segurança e a higiene do trabalho (PADILHA, 2002).

Desta feita, o trabalhador docente sofre não somente com as doenças físicas decorrentes de sua função, tais como, laringite crônica, dor nas costas, 
nódulos nas cordas vocais, faringite, lesões por esforços repetitivos e distúrbios osteomusculares em razão do trabalho, dentre outras.

Entretanto, a grande sensação de mal-estar docente é gerada quando da análise das condições psíquicas do ambiente de trabalho. Estresse, depressão, síndrome de burnout, síndrome do pânico, dentre outra doenças psíquicas decorrentes da função laboral, são os principais fatores que levam os professores a pedir afastamento da sala de aula.

Não há o que se falar em valorização dos profissionais do saber sem que sejam observadas condições de trabalho adequadas.

A necessidade de valorização do trabalho docente decorre do imperativo constitucional de assegurar a todos uma vida digna, bem como implica nas condições mínimas do exercício para a profissão.

\section{CONSIDERAÇÕES FINAIS}

Pelas considerações levantadas na presente análise, destacou-se a relevância e essencialidade da função docente na implementação do direito social à educação. As normas de proteção ao trabalho do docente no Brasil foram elaboradas em consonância com o princípio basilar do Estado Democrático de Direito, qual seja, a prevervação da dignidade da pessoa humana, sendo que sua extensão abrange a qualidade do ambiente de trabalho dos professores brasileiros.

A proteção constitucional dada ao meio ambiente, traduz-se também como defesa da humanização do trabalho, exigindo uma mudança de postura ética, na consideração de que o homem está à frente dos meios de produção, resgatando-se o habitat laboral como espaço de construção de bem-estar e dignidade daquele que labora.

Ressaltou-se que os reais desígnios do Poder Público quando da normatização das garantias ao pleno exercício da função do magistério, vislumbram-se em meramente normatizar e regulamentar a organização laboral, sendo que deveria propugnar a eficiência quando da realização do trabalho digno dos profissionais da educação.

A nova organização laboral de ensino tem contribuido para com a precarização do trabalho docente, eis que impregnada por uma ideologia de mercado, a qual transformou a nobre função do magistério em uma mercadoria. 
A condição de trabalho precário observada pelos profissionais do saber é compreendida na flexibilização da atividade docente, corroborada pelos fenômenos da desprofissionalização da função do magistério, comunitarismo, privatização do ensino e estagnação salarial.

A desvalorização do professor está imersa no centro da sociedade brasileira, e, desta forma, este problema é percebido também no âmbito jurídico, visto que há a falta de eficácia das normas e princípios garantidores da valorização do trabalho docente.

O que se depreende do cenário brasileiro é a falta de comprometimento do Poder Público para com a eficácia dessas normas, tornando inválidas as garantias contitucionais e infralegais do ordenamento brasileiro, que foram elaboradas com fincas no princípio da dignidade da pessoa humana, quando da sua extensão ao meio ambiente de trabalho docente.

Embora não se vislumbre perspectivas de superação em curto prazo, foi possível elaboração de algumas propostas de valorização do trabalho docente.Resta asseverar que o implemento de tais propostas é fruto da junção dos esforços socias com o verdadeiro apoio do Poder Público, compreendido como aquele que deve zelar pela garantia dos direitos fundamentais e dar eficácia do sistema normativo brasileiro.

As propostas elaboradas se resumem a uma tentativa de promover a valorização do trabalho do professor, visto que consistiu na conjunção de um novo conjunto de valores com a concessão de maior autonomia ao docente, atreladas a mecanismos de incentivo, tais como, a melhora na formação dos profissionais de ensino e consolidação das relações de emprego quando da realização do trabalho dos educadores.

Estabelecer um novo conjunto de valores é fazer a sociedade tomar conhecimento do papel essencial da função docente, sendo que, conforme a Constituição Fedaral, o exercício da profissão do magistério deve ser pautado no princípio da valorização do corpo docente, porém há a necessidade do estabelecimento de valores que corroborem para com a valorização dos profissionais do ensino.

Embora sejam estabelecidos valores que objetivam a valorização social do professor, mecanismos estruturais da função docente devem ser implementados, como a concessão de maior autonomia didática ao docente e um fortalecimento na formação dos profissionais de ensino, visto que devem ser oportunizados aos professores a credibilidade de sua profissão. 
As relações de emprego pertinentes ao exercício da função docente devem proporcionar ao professores a segurança de um trabalho digno, em consonância com os dispositivos trabalhistas, com fincas a consolidação de um trabalho exercido em respeito a importância do trabalho humano.

Por último, tentou-se ressaltar a importância da garantia de um salário em conformidade com a complexidade da função docente, uma vez que a valorização do magistério inicia-se quando é oportunizada à categoria dos professores a percepção de remuneração condigna.

Tratar os professores com dignidade e respeito é cuidar da efetivação de seus direitos, é fornecer meios de um exercício profissional em conformidade com o princípio da dignidade humana. Além de intensificar o adoecimento do corpo docente brasileiro, a qualidade do ensino também tornou-se precária, sendo inafastável o empobrecimento cultural da nação brasileira.

\section{REFERÊNCIAS}

APEOESP-Associação dos Professores do Estado de São Paulo. Disponível em: <http://www.apeoesp.gov.br>.

BOSI, Antônio de Pádua. Precarização e intensificação do trabalho no Brasil recente: Ensaios sobre o Mundo dos Trabalhadores. 1.ed. Cascavel: Edunioeste, 2001.

BRASIL. Consolidação das Leis do Trabalho. Organização dos textos de Renato Saraiva. 3.ed. Rio de Janeiro: Forense; São Paulo: Método, 2011.

CALDERÓN, Adolfo Ignacio. Amigos da escola: ações e reações no cenário educacional. In: Reunião Anual da Anped, 30a, 2007, Caxambú. Trabalhos apresentados G5: Estado e Política Educacional, Caxambú, 2007.

\section{CARRION, Valentin. Comentários à consolidação do das leis do} trabalho. 33. ed. atual. por Eduardo Carrion. São Paulo: Saraiva, 2008.

COSTA, Patrícia Gomes; GERMANO, Amédis. Afastamento dos professores de $5^{a}$ à $8^{a}$ séries da rede municipal de Ipatinga da sala de 
aula: principais causadores. Revista Brasileira de Saúde Ocupacional. São Paulo, 2009. In: CONGRESSO DE LETRAS, 6., 2007, Argentina. Anais eletrônicos. Brasil: UNEC, 2007. Disponível em: <http:// bibliotecadigital.unec.edu.br >. Acesso em: 17 fev. 2013.

DELGADO, Maurício Godinho. Curso de direito do trabalho. 11. ed. São Paulo: Ltr, 2012.

FACCI, Marilda Gonçalves Dias. Valorização ou esvaziamento do trabalho do professor?:um estudo crítico-comparativo da teoria do professor reflexivo, do construtivismo e da psicologia vigotskiana. Campinas: Autores Associados, 2004.

GURGEL, Cláudio. A educação entre o valor e a mercadoria. Universidade e Sociedade. ano XVI, n 39, fev, 2007. Disponível em: < http:// portal.andes.org.br>. Acesso em: 04 mar. 2013.

HYPOLITO, Álvaro Moreira; VIEIRA, Jarbas Santos; Pizzi, Laura Cristina Vieira. Reestruturação curricular e autointensificação do trabalho docente. Currículo sem Fronteiras. v.9, n.2,Jul/Dez 2009. Disponível em: <http://www.curriculosemfronteiras.org>. Acesso em: 16 de fev. 2013.

IBRAHIM, Fábio Zambitte. Curso de direito previdenciário. 17.ed. Rio de Janeiro: Impetus, 2012.

KELSEN, Hans. Teoria Geral das Normas. Porto Alegre: Fabril, 1986.

MARTINS, Sergio Pinto. Comentários à CLT. 13. ed. São Paulo: Atlas, 2009.

MELLO FILHO, José Celso de. Constituição Federal Anotada. 2 ed. São Paulo: Saraiva, 1986.

MORAES, Alexandre. Direito Constitucional. 26.ed. São Paulo: Atlas, 2010. 
NOVELINO, Marcelo. Direito Constitucional. 5.ed Rio de Janeiro: Forense; São Paulo: Método, 2011.

OLIVEIRA, D.A. A reestruturação do trabalho docente: precarização e flexibilização. Educação \& Sociedade, Campinas, v. 25, n. 89, 2004. Disponível em: < http://www.scielo.br>. Acesso em 07 mar. 2004.

PADILHA, Norma Sueli. Relação de Trabalho entre o Professor e a Instituição de Ensino: recordando os direitos especiais do professor. Disponível em: <http://www.estudosdotrabalho.org/anais6seminariodo trabalho/flaviobentoenormasuelipadilha.pdf>. Acesso em 06 dez.2012.

PARO apud BENTO, Flávio; PADILHA, Norma Sueli. Relação de Trabalho entre o Professor e a Instituição de Ensino: recordando os direitos especiais do professor. Disponível em: <http://www.estudosdo trabalho.org/anais6seminariodotrabalho/flaviobentoenormasuelipadilha.pdf>. Acesso em 25 out.2012.

PESSANHA, Eurize Caldas. Ascensão e queda do professor. 2.ed. São Paulo: Cortez, 1997.

PINTO, Marina Barbosa. A crise de acumulação de capital e o papel social da universidade brasileira. Universidade e Sociedade. ano XVI, $\mathrm{n}^{\circ}$ 39, fev, 2007. Disponível em: < http://portal.andes.org.br>. Acesso em: 04 mar. 2013.

REALE, Miguel. Lições preliminares de direito. 25.ed. São Paulo: Saraiva, 2000.

SANT’ANA, Raquel Santos (Orgs.); LOURENÇO, Edvânia; NAVARRO, Vera, BERTANI, Iris; SILVA, José F.S. da. O Avesso do Trabalho II. 1.ed. São Paulo: Expressão Popular, 2010.

SILVA, José Afonso. Curso de Direito Constitucional Positivo. 32. ed. São Paulo: Malheiros, 2009.

TEIXEIRA apud SILVA, José Afonso. Curso de Direito Constitucional Positivo. 32. ed. São Paulo: Malheiros, 2009. 
VIEIRA, Alboni Marisa DudequePianovski; GOMIDE, AngelaGalizzi Vieira. História da formação de professores no Brasil: o primado das influências externas. In: EDUCERE, 8., 2008, Curitiba, PR. Anais... Disponível em: <http:/www.pucpr.br/eventos/educere/educere2008/anais/ pdf/93_159.pdf $>$. Acesso em: 12 out. 2012.

Artigo recebido em: 27/11/2013 Aprovado para publicação em: 08/04/2014

Como citar: OLIVEIRA, Lourival José. PIRES, Ana Paula Vicente. Da precarização do trabalho docente no Brasil e o processo de reestruturação produtiva. Revista do Direito Público. Londrina, v.9, n.1, p.73100, jan./abr.2014. DOI: 10.5433/1980-511X.2014v9n1p73. 